\title{
Twenty-two years' experience with childhood-onset SLE in a developing country: are outcomes similar to developed countries?
}

\author{
Prayong Vachvanichsanong, ${ }^{1}$ Pornsak Dissaneewate, ${ }^{1}$ Edward McNeil ${ }^{2}$
}

1Department of Pediatrics, Prince of Songkla University, Hat Yai, Songkla, Thailand ${ }^{2}$ Epidemiology Unit, Prince of Songkla University, Hat Yai, Songkhla, Thailand

\section{Correspondence to}

Prayong Vachvanichsanong,

Faculty of Medicine,

Department of Pediatrics,

Prince of Songkla University, Hat Yai, Songkhla 90110, Thailand;

vprayong@gmail.com

Accepted 21 July 2010 Published Online First 7 October 2010

\begin{abstract}
Introduction The outcome of systemic lupus erythematosus (SLE) has dramatically improved since the introduction of corticosteroids; however, although many regimens of treatment have been supplemented, the mortality has not improved further.

Objective To describe the severity and outcome in patients diagnosed with SLE aged $\leq 18$ years in a group of Thai children, compare gender and age differences, and our outcomes with those from developed countries. Methods The authors retrospectively reviewed the files of patients aged $\leq 18$ years diagnosed with SLE admitted to Songklanagarind University Hospital in southern Thailand, for the period 1985-2007. Patient survival rates were calculated.

Results There were 213 SLE patients, 41 males and 172 females, average age $11.6 \pm 2.6$ years, with a median follow-up of 3.6 years. Outcomes were alive (109), lost to follow-up (22), referred (31) or deceased (51). Of the patients who were alive, 23 were not on any treatment, 59 were on prednisolone alone while 27 were on prednisolone plus some other immunosuppressive drug. Total survival rates were $88 \%, 76 \%$ and $64 \%$ at 2,5 and 10 years, respectively. Males had significantly worse survival than females at 2 and 5 years $(78 \%$ vs $91 \%$ and $58 \%$ vs $80 \%$, respectively, $p=0.018$ ). There were no differences in mortality between age groups. The 5-year survival rates in the periods 1985-1993, 1994-2000 and 2001-2007 were not significantly different.
\end{abstract}

Conclusion This retrospective study of patients with SLE in southern Thailand showed different outcomes compared to some studies and similar survival rates and treatment status to other studies, with one-fourth of surviving patients being free of medication.

\section{INTRODUCTION}

Systemic lupus erythematosus (SLE) is an autoimmune connective tissue disease, usually with multiple-organ involvement. Although the disease is more common in adults, it is more severe in children and has a much poorer prognosis, probably due to renal involvement. ${ }^{12}$ The worldwide 5-year survival rate for SLE in adults in the period 1953-1969 was only 49\%, but in the years that followed there was a dramatic improvement when corticosteroids were introduced for SLE treatment. ${ }^{3}$ However, since then the global 5 -year survival rates have gradually improved-they were $82 \%, 86 \%$ and $92 \%$ in $1970-1979,1980-$ 1989 and 1990-1995, respectively. ${ }^{3}$ A report by Yang et al in 1994 on 167 SLE children had 5-year patient and renal survival rates of $91 \%$ and $93 \%$,

\section{What is already known on this topic}

Systemic lupus erythematosus (SLE) is not a common disease, more often occurring in adults, usually with delayed diagnosis; survival rates vary by population, severity of disease and treatment regimen.

\section{What this study adds}

We provide a retrospective 22-year study of a large group of SLE patients from a single tertiary care centre in a developing country with limited resources, and compare the results with those from developed and developing countries.

respectively. Disappointingly, the outcomes of SLE have not improved much even though many additional immunosuppressive drugs have been tried. The best treatment regimens for SLE have therefore not been achieved, and most paediatricians are still unhappy with the current level of treatment outcomes and continue to search for more effective treatments. New drugs are regularly being introduced; however, it will take decades to know how truly effective they are, since SLE is a chronic condition and therefore the outcome and side effects of drugs used in the long term require long-term evaluation. Evaluation is further hindered because SLE is not a very common disease; thus finding sufficient numbers of patients in one place for meaningful analysis is a problem for researchers. Widespread networking could facilitate this process.

Our university hospital serves as the only tertiary care facility in the south of Thailand, thus our Pediatric Nephrology Unit sees most SLE patients from this area, since a high percentage of childhood SLE patients have renal involvement, which determines morbidity and mortality, and for which our institution provides the only high-level treatment in southern Thailand. We have previously reported on 20 SLE children with unique presentations, ${ }^{5}$ and herein we offer a longer, 22-year retrospective study to describe the severity and outcomes of childhood-onset SLE from the south of Thailand 
to help us understand better the clinical course severity and outcomes of this SLE treatment programme, and also compare them with other studies from developed and developing countries.

\section{PATIENTS AND METHODS}

We retrospectively reviewed the patient files of children who fulfilled 4 or more of the 11 American College of Rheumatology revised criteria for the classification of SLE, ${ }^{6}$ and who attended the Pediatrics Department at Songklanagarind University Hospital in southern Thailand between February 1985 and October 2007. The patients were divided into three periods: 1985-1993, 1994-2000 and 2001-2007. In the first 9 -year period there were 24 patients. The remaining 14 years were divided into two equal periods of 7 years, the first with 76 and the second with 113 patients. Only patients aged less than 18 years at presentation to the hospital were included in the study. We created age groups of $<9$ years, $>9-12$ years, $>12-14$ years and $>14-18$ years in order to create roughly equal-sized groups. Demographic data, follow-up period and the status of the patients when last seen were recorded.

Patients who were referred to other medical centres or to the Department of Internal Medicine and never returned to our clinic for follow-up were considered as alive at their last follow-up visit to our clinic for the purposes of calculating survival rates. Patient and kidney survival rates were calculated using the Kaplan-Meier method. The log-rank test was used to compare survival rates between groups. The International Society of Nephrology and the Renal Pathology Society morphologic classification of lupus nephritis (LN) was followed in general; however, in this study we classified our patients into the major recognised LN groups to avoid very small numbers in many subgroups. Our final classification scheme was: class I was normal glomeruli, and classes II-VI were mesangial proliferative, focal segmental, diffuse proliferative, membranous and advanced sclerosing glomerulonephritis, respectively. ${ }^{7}$ Chronic kidney disease was defined by a serum creatinine concentration $>2$ times higher than the upper limit of normal values for the patient's age, which persisted for more than 3 months. Ethics approval for this study was granted by the Institute Review Board, Faculty of Medicine, Prince of Songkla University.

Statistical analysis was performed using R software V.2.8.1. ${ }^{8}$ $\chi^{2}$ Test or Fisher's exact test was used for comparing differences between groups, Kaplan-Meier survival curve for survival rate and log-rank test for comparing survival differences. A p value $<0.05$ was considered significant.

\section{RESULTS}

There were 213 SLE patients seen at our clinic during the study period, 41 males (19.2\%) and 172 females (80.8\%), average age of diagnosis $11.6 \pm 2.6$ years (range 3.6-18.0). Table 1 shows the distribution of SLE patients by age group and gender. Females predominated and the ratio of females to males tended to increase with age, but this was not statistically significant $(\mathrm{p}=0.27)$.

For the 172 patients who had an initial renal biopsy performed, there were 9, 81, 4, 63 and 13 patients categorised as classes I-V of LN, respectively, as well as one end stage renal disease (ESRD) and one IgM nephropathy. When clinical progression of disease was evident, a repeat biopsy was performed. When these repeat biopsies were considered, and the most severe class between all biopsies used, the numbers of patients with LN classes I, II, III, IV and V were 8, 62, 5, 81 and 13 , respectively.

Table 1 shows outcomes at the final recorded follow-up, defined as alive (109), lost to follow-up (22), referred (31) or deceased (51). Of the patients who were alive, $23(21.1 \%)$ were not on any treatment, 59 (54.1\%) were on prednisolone alone while 27 (24.8\%) were on prednisolone plus some other immunosuppressive drug.

At 2, 5 and 10 years the overall survival rates were $88 \%$ (95\% CI $84 \%$ to $93 \%$ ) ( $\mathrm{N}=142), 76 \%$ (95\% CI $69 \%$ to $83 \%)$ $(\mathrm{N}=75)$ and $64 \%(95 \%$ CI $55 \%$ to $75 \%)(\mathrm{N}=30)$, respectively (figure 1). However, males had a significantly worse survival rate than females at 2 and 5 years (78\% vs $91 \%$ and $58 \%$ vs $80 \%$, respectively, $\mathrm{p}=0.018$ ) (figure 2 ). There were no differences in survival rates between age groups $(p=0.9)$.

Table 2 categorises the SLE patients for each period and shows that the overall 2- and 5-year survival rates between the three periods were not significantly different $(p=0.09)$.

There were 46 patients who developed renal failure; a flowchart of these is shown in figure 3. Altogether 14 patients (6.6\%) developed chronic kidney disease, leading to renal survival rates of $96 \%$ and $93 \%$ at 2 and 5 years, respectively (figure 4).

\section{DISCUSSION}

In this study we analysed 213 patients with childhood onset SLE. As table 2 shows, the number of SLE patients

Table 1 Age groups, follow-up periods and outcome by gender in 213 systemic lupus erythematosus patients

\begin{tabular}{|c|c|c|c|c|}
\hline & Total & Male & Female & Ratio F:M \\
\hline Total & 213 & 41 & 172 & $4.2: 1$ \\
\hline \multicolumn{5}{|l|}{ Age group (years) } \\
\hline$\leq 9$ & 37 & 11 & 26 & $2.4: 1$ \\
\hline$>9-12$ & 63 & 13 & 50 & $3.8: 1$ \\
\hline$>12-14$ & 74 & 11 & 63 & $5.7: 1$ \\
\hline$>14-18$ & 39 & 6 & 33 & $5.5: 1$ \\
\hline \multicolumn{5}{|l|}{ Follow-up time } \\
\hline Median (range) & $3.6(0-21.4$ years $)$ & 2.2 (7 days to 19.4 years) & 3.9 (0-21.4 years) & \\
\hline \multicolumn{5}{|l|}{ Outcome } \\
\hline Alive & 109 & 19 & 90 & \\
\hline Referred & 31 & 6 & 25 & \\
\hline Lost to follow-up & 22 & 2 & 20 & \\
\hline Deceased & 51 & 14 & 37 & \\
\hline
\end{tabular}




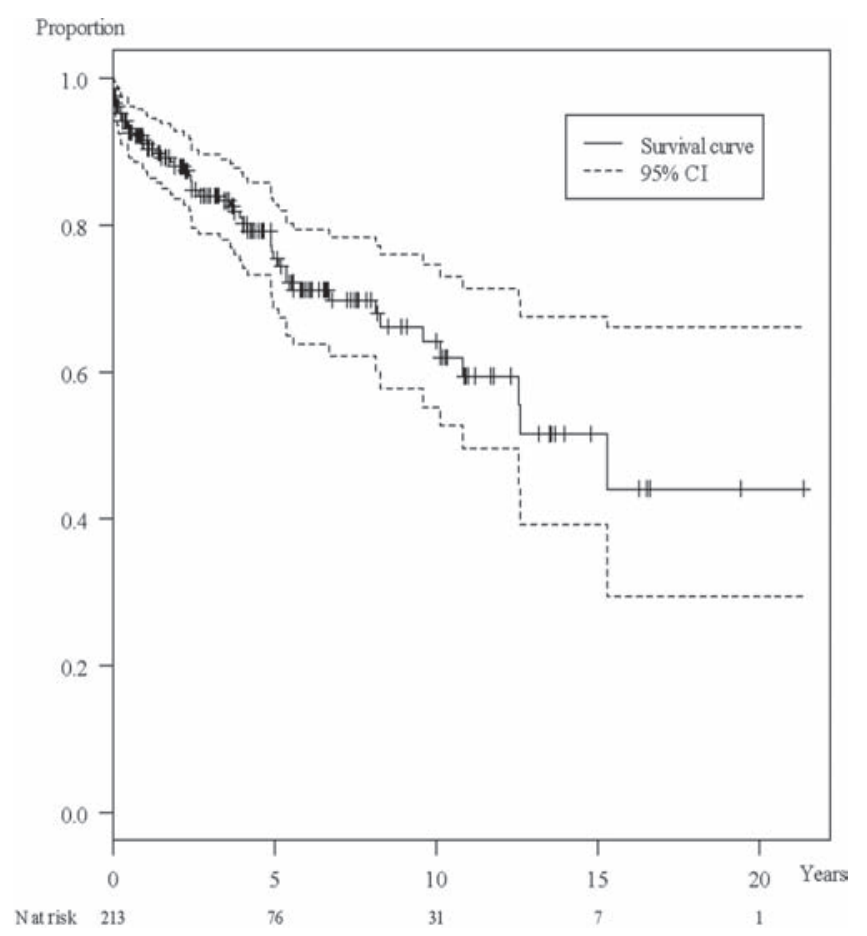

Figure 1 Kaplan-Meier survival curve showing probability of overall patient survival and number of patients ( $\mathrm{N}$ at risk) followed up during each time period. The vertical ticks represent censored observations.

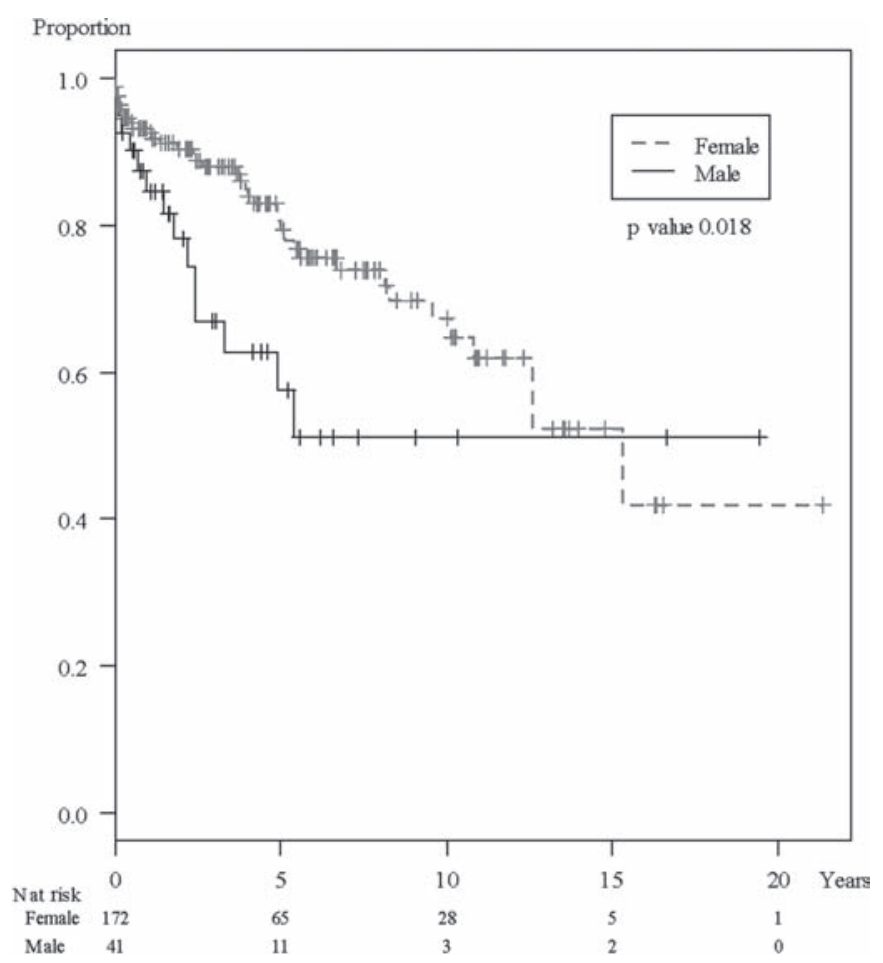

Figure 2 Kaplan-Meier survival curve showing probability of patient survival by sex and number of patients ( $\mathrm{N}$ at risk) followed up during each time period. The vertical ticks represent censored observations.

Table 2 The outcome of 213 systemic lupus erythematosus patients by mortality and survival rates at 2, 5 and 10 years in each period

\begin{tabular}{|c|c|c|c|c|}
\hline & Total & $1985-1993$ & $1994-2000$ & 2001-2007 \\
\hline N & 213 & 24 & 76 & 113 \\
\hline \multicolumn{5}{|l|}{ Follow-up period } \\
\hline Median (range) & 3.6 (0-21.4 years) & 12.9 ( 9 days to 21.4 years) & 5.6 (7 days to 12.3 years) & 2.2 (0-6.8 years) \\
\hline$\leq 2$ years & 73 & 3 & 18 & 52 \\
\hline$>2-5$ years & 65 & 3 & 17 & 45 \\
\hline$>5-10$ years & 45 & 3 & 26 & 16 \\
\hline$>10$ years & 30 & 15 & 15 & 0 \\
\hline \multicolumn{5}{|l|}{ Survival rate } \\
\hline At 2 years & $140(89 \%)$ & $21(88 \%)$ & $58(85 \%)$ & $61(91 \%)$ \\
\hline At 5 years & $75(76 \%)$ & $18(75 \%)$ & $41(71 \%)$ & $16(77 \%)$ \\
\hline At 10 years & $30(64 \%)$ & $15(66 \%)$ & $15(57 \%)$ & NA \\
\hline
\end{tabular}

NA, not applicable.

increased after 1993, the year when a paediatric nephrologist first became regularly available at our institution. SLE is predominately a female disease, with the adult female to male ratio varying from $7: 1$ to $18: 1$ and in children usually from $3: 1$ to $5: 1$, comparable to our study of $4.2: 1$, although some reports have noted higher childhood ratios closer to adult levels. ${ }^{9-11}$

Table 2 shows a lack of improvement in outcomes over the three periods. This does not necessarily reflect a lack of advances in treatment, but may be due to the differences in severity of cases between the three periods. In addition, the number of cases in the early time period was low and most probably the selection of cases was different at that time. It is also not known whether more severe cases were referred in the latter time periods or that less severe patients were referred because they survived for a long time.
Many studies have reported on SLE outcomes; however, comparisons are difficult due to differing numbers of patients and wide variations in parameters such as study methodology, categorisations, definitions of outcomes, ranges of follow-up and treatment regimens. In this study the overall mortality was $23.9 \%$. This is comparable to other studies, for instance, the mortality in 52 Egyptian children with SLE (80.8\% with LN) was similar at $22.2 \%,{ }^{9}$ and a report of 153 Taiwanese SLE children with an average follow-up time of $6.1 \pm 9.0$ years showed a mortality of $50 / 153=32.7 \% .{ }^{12}$ There are studies with different findings, for instance, a report from Canada which showed a mortality in 67 children of only $6.0 \%$ with a follow-up time of 11.0 years $(5-12) .{ }^{13}$

Table 3 shows the outcomes of treatment in various studies with varying study populations, follow-up periods and treatments. This study was comparable to the study in 


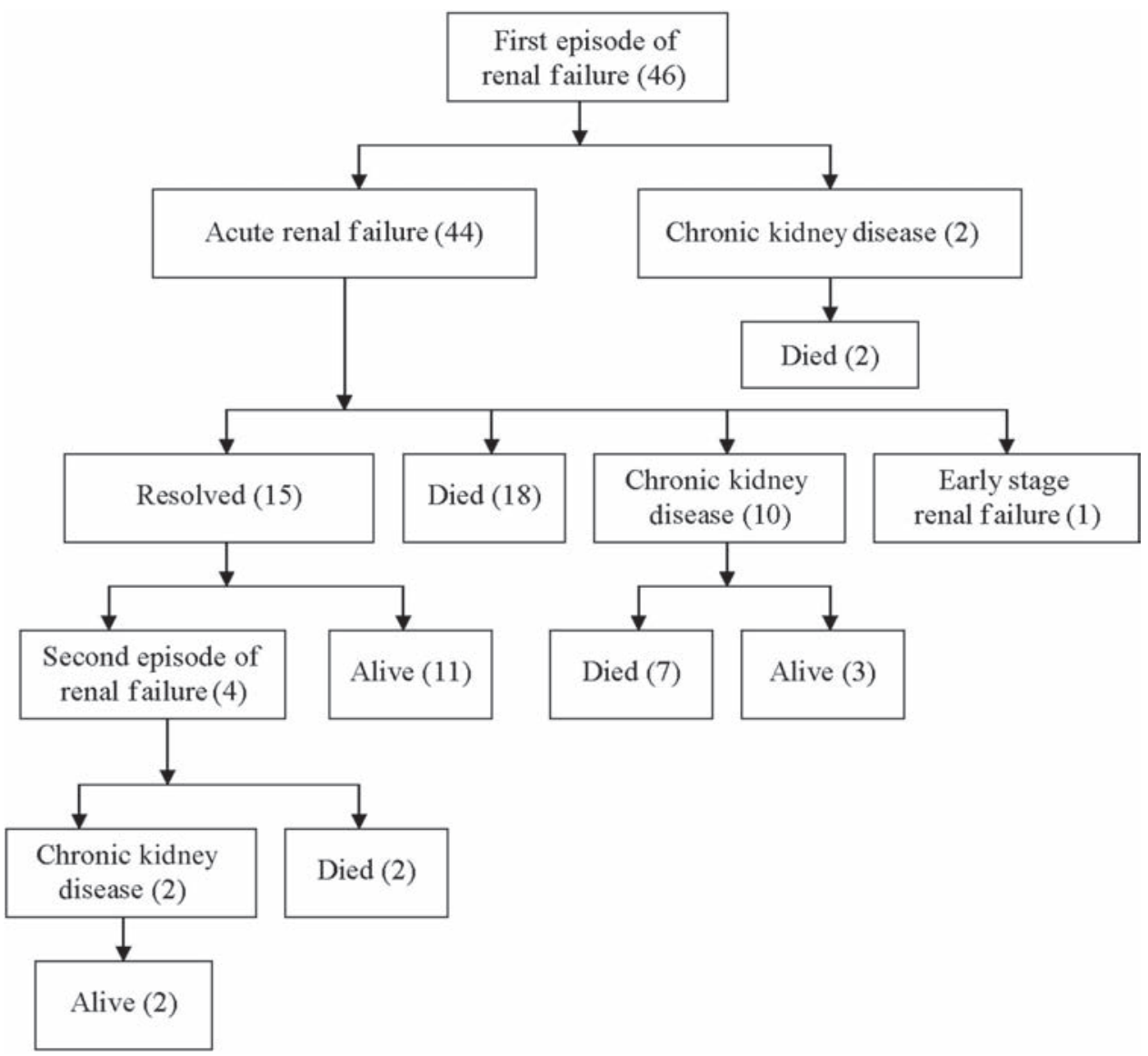

Figure 3 Flowchart of patients who developed renal failure, according to chronic kidney disease and acute renal failure.

153 Taiwanese children (2003), while the two other Asian countries, Korea and Taiwan (1994), and Hong Kong had better survival rates. ${ }^{4} 1012-17$

Multiple risk factors have been reported to indicate poor prognosis, for example, gender, hypertension, non-Caucasian, presence of renal insufficiency and diffuse proliferative glomerulonephritis. ${ }^{13} 1819$ A report from Turkey showed persistent hypertension lasting more than 6 months and anaemia were poor prognostic factors, while gender and younger age at onset were not. ${ }^{17}$ The present study did not evaluate independent risk factors; however, the survival rates between sexes were significantly different, while age groups were not.

We have previously reported finding 64 infection complications in 32 out of 84 SLE patients whose condition indicated treatment with intravenous cyclophosphamide (IVCY), a figure which is higher than in other studies. ${ }^{20} 21$

Increasing survival rates correspond to increases in morbidity and consequences of chronic disease since the patients have a longer time to develop such conditions. ${ }^{22}$ Long-term use of corticosteroids and immunosuppressive therapy increase the morbidity and change the proximate mortality from SLE to opportunistic infection. ${ }^{2} 13$

As LN is a major cause of morbidity and mortality in SLE, consideration of not only patient survival but also renal survival is essential for evaluation of SLE treatment. A study of azathiaprine therapy in 26 SLE adults in Norway with a median follow-up time of 119 months showed renal survival rates of $92 \%, 87 \%$ and $87 \%$ at 5,10 and 15 years, respectively. ${ }^{23}$ A study in 128 children from China found renal survival rates of $94 \%, 87 \%$ and $82 \%$ at 5,10 and 15 years, respectively. ${ }^{15}$

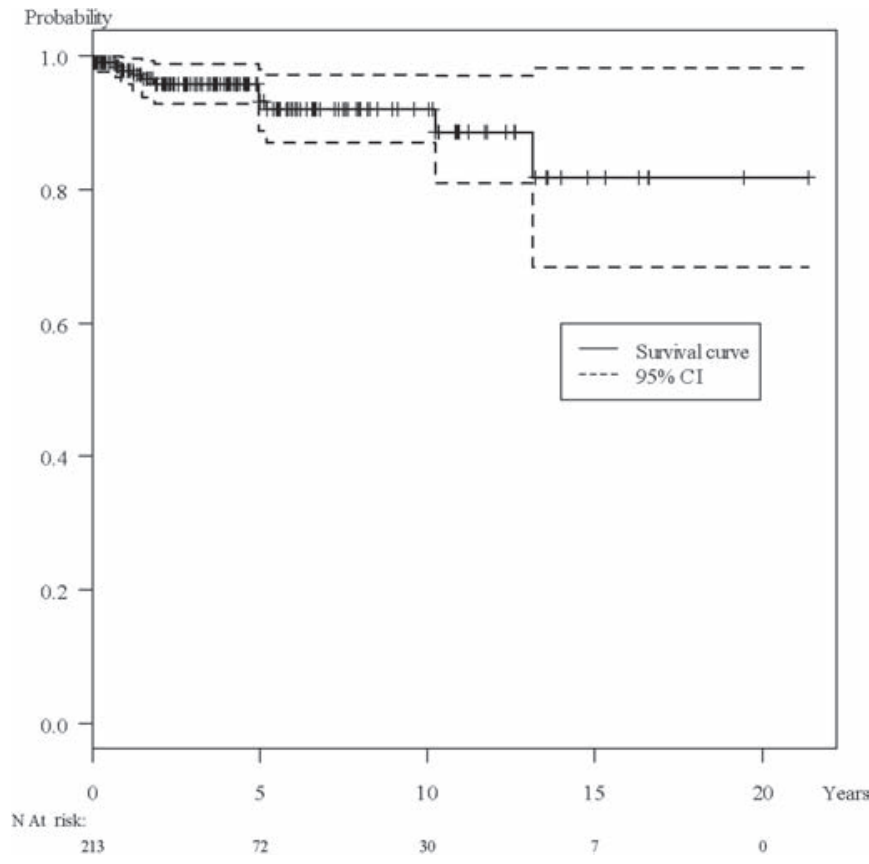

Figure 4 Kaplan-Meier survival curve showing probability of overall renal survival and number of patients ( $\mathrm{N}$ at risk) followed up during each time period.

Neumann et al 24 reported on 149 LN adults whose 5-, 10- and 15 -year survival rates were $90 \%, 81 \%$ and $70 \%$, respectively. The present study found renal survival rates of $96 \%, 93 \%$, 
Table 3 Comparison of survival rates among outcome studies in systemic lupus erythematosus patients

\begin{tabular}{|c|c|c|c|c|c|c|c|c|c|c|c|}
\hline \multirow[b]{2}{*}{ Country } & \multirow[b]{2}{*}{ Year } & \multirow[b]{2}{*}{ References } & \multirow[b]{2}{*}{$\mathbf{N}$} & \multirow[b]{2}{*}{ Follow-up time } & \multirow[b]{2}{*}{ Age } & \multicolumn{5}{|c|}{ Survival rates } & \multirow[b]{2}{*}{ Remarks } \\
\hline & & & & & & 1 Year & 2 Years & 5 Years & 10 Years & 15 Years & \\
\hline Thailand & 2010 & This study & 213 & $\begin{array}{l}\text { Median } 3.6 \\
\text { (range } 0-21.4 \text { ) years }\end{array}$ & $<18$ years & 92.1 & 88.6 & 75.7 & 64.3 & 50.9 & $\begin{array}{l}\text { All SLE, mixed } \\
\text { therapy }\end{array}$ \\
\hline Korea & 2007 & 14 & 77 & Mean $8.3 \pm 4.4$ years & Mean $11.9 \pm 3.0$ years & NA & NA & 95.4 & 91.8 & NA & $\mathrm{LN}$ \\
\hline Hong Kong & 2006 & 15 & 128 & $\begin{array}{l}\text { Median } 5.3 \\
\text { (range 1-16.5) years }\end{array}$ & Range $3.6-18.6$ years & NA & NA & 95 & 92 & 92 & $\begin{array}{l}G: B 120: 8,24 \\
F / U \geq 10 \text { years }\end{array}$ \\
\hline Taiwan & 2004 & 16 & 72 & Mean $7.12 \pm 0.51$ years & $<18$ years & NA & NA & 63 & 53 & NA & LN III, IV and V \\
\hline Taiwan & 2003 & 12 & 153 & Mean $6.11 \pm 9.02$ years & Mean $13.1 \pm 6.0$ years & NA & NA & 75.5 & 63.1 & NA & 50 deaths \\
\hline Canada & 2002 & 13 & 67 & $\begin{array}{l}\text { Mean } 11 \\
\text { (range 5-19) years }\end{array}$ & $\begin{array}{l}\text { Mean } 13.2 \\
\text { (range } 4-17 \text { ) years }\end{array}$ & NA & NA & 97 & 95 & 90 & $\begin{array}{l}\mathrm{G}: \mathrm{B}=3.8: 1,4 \\
\text { deaths, } 6 \text { ESRD }\end{array}$ \\
\hline Turkey & 2001 & 17 & 43 & Mean $7.2 \pm 2.8$ years & Mean $12.0 \pm 2.8$ years & NA & NA & 83.7 & NA & NA & $\begin{array}{l}\text { with renal } \\
\text { biopsy G:B 39:4 }\end{array}$ \\
\hline
\end{tabular}

B, boys; ESRD, end stage renal disease; G, girls; LN, lupus nephritis; NA, not applicable.

$92 \%$ and $82 \%$ at $2,5,10$ and 15 years, respectively, comparable to or even better than some other studies, although the overall patient survival was worse. Ninety-six patients in this study had severe LN or other organ involvement and were treated with IVCY. IVCY was reported as very effective in LN in some initial studies, ${ }^{25-27}$ but other meta-analysis studies have found it to be not as good as these initial studies and also noted some serious long-term side effects. ${ }^{28-30}$ However, a more recent study on 72 SLE children from Taiwan in 2004 showed a favourable outcome using IVCY. ${ }^{16}$ The number of patients, severities of disease, follow-up periods and regimens of therapy should be carefully noted when comparing studies. The findings from this study suggest that treatment regimens need to be carefully evaluated in order to determine the optimal benefit of each treatment. Walking the tightrope every day as physicians dealing with difficult diseases we have to find a reasonable balance between the benefits and adverse reactions/complications from the treatments we offer. In the event of inflammation of any major organ, judicious use of aggressive therapy can help decrease the long-term organ morbidity. During the immunosuppressive period, the physician needs to monitor patients undergoing any invasive treatment closely for potential complications, especially infections.

The one definite factor that gave the patients in this study a poorer prognosis was (and remains) the prohibitively high cost of renal replacement therapy in chronic kidney disease in our hospital (and in fact all of Thailand).

SLE is a treatable disease but not unfortunately curable at this time, with the best results using the most advanced treatments currently available being simply an 'inactive' or 'disease under control' status, as in this study, with only one-fourth of patients being free of medication, half requiring prednisolone to control their symptoms and the remaining one-fourth needing prednisolone combined with other immunosuppressive drugs. The very long term course of 110 SLE patients in one study from the UK (mean follow-up time 15.4 years; range 10-32 years) showed a mortality of 40/110 $(36.4 \%)$, and of the surviving patients $9(12.9 \%)$ had ESRD, and only $11(15.7 \%)$ were free of medication, with $17(24.3 \%)$ on prednisolone alone and 31 (44.3\%) on prednisolone with other immunosuppressive drugs. ${ }^{3} 31$

Comparison of outcomes with other studies is difficult because of differences in patient populations. Each study population is unique. Patients may be of a different race, may have a different severity of disease and be given different treatment regimes. In spite of this limitation, we have nevertheless tried to make certain comparisons, and believe that we have done so with some success.

\section{CONCLUSION}

SLE is known to be a serious disease in children with an unacceptably high mortality, and an optimal treatment has not yet been found. This 22 -year retrospective study from the south of Thailand shows a similar survival rate and long-term patient status with earlier long-term studies from developed countries, with only one-fourth of surviving patients being free of medication. Research into this disease to improve outcomes is challenging. The impact of the disease needs to be balanced with the impact of aggressive treatments.

\section{Competing interests None.}

Ethics approval This study was conducted with the approval of the Prince of Songkla University.

Provenance and peer review Not commissioned; externally peer reviewed.

\section{REFERENCES}

1. Perfumo F, Martini A. Lupus nephritis in children. Lupus 2005:14:83-8.

2. Klein-Gitelman M, Reiff A, Silverman ED. Systemic lupus erythematosus in childhood. Rheum Dis Clin North Am 2002;28:561-77, vi-vii.

3. Cameron JS. Lupus nephritis. J Am Soc Nephrol 1999;10:413-24.

4. Yang LY, Chen WP, Lin CY. Lupus nephritis in children-a review of 167 patients. Pediatrics 1994;94:335-40.

5. Vachvanichsanong $\mathbf{P}$, Dissaneewate P. Childhood systemic lupus erythematosus in songklanagarind hospital: a potential unique subgroup. Clin Rheumatol 1993;12:346-9.

6. Hochberg MC. Updating the American College of Rheumatology revised criteria for the classification of systemic lupus erythematosus. Arthritis Rheum 1997:40:1725.

7. Weening JJ, D'Agati VD, Schwartz MM, et al. The classification of glomerulonephritis in systemic lupus erythematosus revisited. J Am Soc Nephrol 2004; 15:241-50

8. R Development Core Team. R: A Language and Environment for Statistical Computing. R Foundation for Statistical Computing, Vienna, Austria. 2006. http:// www.R-project.org (accessed 20 August 2008).

9. Bakr A. Epidemiology treatment and outcome of childhood systemic lupus erythematosus in Egypt. Pediatr Nephrol 2005;20:1081-6.

10. Bogdanovic $\mathbf{R}$, Nikolic V, Pasic S, et al. Lupus nephritis in childhood: a review of 53 patients followed at a single center. Pediatr Nephrol 2004;19:36-44.

11. Hiraki LT, Benseler SM, Tyrrell PN, et al. Clinical and laboratory characteristics and long-term outcome of pediatric systemic lupus erythematosus: a longitudinal study. J Pediatr 2008;152:550-6. 
12. Wang LC, Yang YH, Lu MY, et al. Retrospective analysis of mortality and morbidity of pediatric systemic lupus erythematosus in the past two decades. J Microbiol Immunol Infect 2003;36:203-8.

13. Hagelberg $\mathbf{S}$, Lee $\mathrm{Y}$, Bargman J, et al. Longterm followup of childhood lupus nephritis. J Rheumatol 2002;29:2635-42.

14. Lee BS, Cho HY, Kim EJ, et al. Clinical outcomes of childhood lupus nephritis: a single center's experience. Pediatr Nephrol 2007;22:222-31.

15. Wong SN, Tse KC, Lee TL, et al. Lupus nephritis in Chinese children - a territory-wide cohort study in Hong Kong. Pediatr Nephrol 2006;21:1104-12.

16. Wang LC, Yang YH, Lu MY, et al. Retrospective analysis of the renal outcome of pediatric lupus nephritis. Clin Rheumatol 2004;23:318-23.

17. Emre S, Bilge I, Sirin A, et al. Lupus nephritis in children: prognostic significance of clinicopathological findings. Nephron 2001;87:118-26.

18. Iseki K, Miyasato F, Oura T, et al. An epidemiologic analysis of end-stage lupus nephritis. Am J Kidney Dis 1994;23:547-54.

19. Anonymous. Lupus nephritis: prognostic factors and probability of maintaining life supporting renal function 10 years after the diagnosis. Gruppo Italiano per lo Studio della Nefrite Lupica (GISNEL). Am J Kidney Dis 1992;19:473-9.

20. Laoprasopwattana K, Dissaneewate P, Vachvanichsanong P. Fatal infection in children with lupus nephritis treated with intravenous cyclophosphamide. Pediatr Nephrol 2009;24:1337-43.

21. Opastirakul S, Chartapisak W. Infection in children with lupus nephritis receiving pulse and oral cyclophosphamide therapy. Pediatr Nephrol 2005;20:1750-5.
22. Hiraki LT, Hamilton J, Silverman ED. Measuring permanent damage in pediatric systemic lupus erythematosus. Lupus 2007;16:657-62.

23. Nossent HC, Koldingsnes W. Long-term efficacy of azathioprine treatment for proliferative lupus nephritis. Rheumatology (Oxford) 2000;39:969-74.

24. Neumann K, Wallace DJ, Azen C, et al. Lupus in the 1980s: III. Influence of clinical variables, biopsy, and treatment on the outcome in 150 patients with lupus nephritis seen at a single center. Semin Arthritis Rheum 1995;25:47-55.

25. Lehman TJ, Onel K. Intermittent intravenous cyclophosphamide arrests progression of the renal chronicity index in childhood systemic lupus erythematosus. J Pediatr 2000:136:243-7.

26. Valeri A, Radhakrishnan J, Estes D, et al. Intravenous pulse cyclophosphamide treatment of severe lupus nephritis: a prospective five-year study. Clin Nephrol 1994; 42:71-8.

27. Austin HA, 3rd, Klippel JH, Balow JE, et al. Therapy of lupus nephritis. Controlled trial of prednisone and cytotoxic drugs. N Engl J Med 1986;314:614-19.

28. AI Salloum AA. Cyclophosphamide therapy for lupus nephritis: poor renal survival in Arab children. Pediatr Nephrol 2003;18:357-61.

29. Mok CC, Wong RW, Lau CS. Lupus nephritis in Southern Chinese patients: clinicopathologic findings and long-term outcome. Am J Kidney Dis 1999;34:315-23.

30. MacGowan JR, Ellis S, Griffiths M, et al. Retrospective analysis of outcome in a cohort of patients with lupus nephritis treated between 1977 and 1999. Rheumatology (Oxford) 2002;41:981-7.

31. Bono L, Cameron JS, Hicks JA. The very long-term prognosis and complications of lupus nephritis and its treatment. OJM 1999;92:211-18. 